\title{
A IMPLEMENTAÇÃO DO ENSINO HÍBRIDO NO ENSINO DE INGLÊS DURANTE A FORMAÇÃO DOCENTE
}

\author{
André Firpo Beviláqua (UFPel) \\ Helena dos Santos Kieling (UFPel) \\ Vilson José Leffa (UFPel)
}

Resumo: Desenvolvemos o presente estudo com o objetivo geral de investigar a implementação do modelo Ensino Híbrido (em inglês Blended Learning) de Rotação em um curso de extensão de Língua Inglesa, ministrado por professoras em formação de uma Universidade Federal do Sul do Brasil. No que diz respeito aos objetivos específicos, pretendemos, com este estudo: a) Apresentar os modelos pedagógicos e epistemológicos que norteiam a atividade docente, com ênfase no uso pedagógico de tecnologias; b) Relacionar os modelos pedagógicos e epistemológicos apresentados a priori ao conceito de metodologias ativas, com destaque para o Ensino Híbrido; c) Avaliar em que medida os modelos epistemológicos e pedagógicos, juntamente com metodologias ativas como o Ensino Híbrido, podem potencializar o uso pedagógico de tecnologias na formação inicial de duas professoras. Os resultados mostram a importância da reflexão sobre o uso da tecnologia e de metodologias ativas no ensino da Língua Estrangeira embasados em uma concepção epistemológica relacional (BECKER, 2012) ainda durante a formação docente, bem como sugere a necessidade de mais pesquisas voltadas a esta área.

Palavras-chave: Metodologias Ativas; Ensino Híbrido; Modelos Pedagógicos e Epistemológicos.

Abstract: We developed the present study aiming at investigating the implementation of Rotation Station Blended Learning model in an English Language extension program, taught by student teachers of a federal university in the south of Brazil. Concerning specific goals, we intend to: a) present the pedagogical and epistemological models that guide the teaching activity, emphasizing the pedagogical use of technologies; $b$ ) relate the pedagogical and epistemological models presented a priori to the concept of active methodologies, highlighting Blended Learning; c) evaluate to what extent the pedagogical and epistemological models, 
together with active methodologies, such as Blended Learning, can enhance the pedagogical use of technologies in the initial training of two teachers. Results show the importance of reflection on the use of technology and active methodologies in the teaching of foreign language based on a relational epistemological conception (BECKER, 2012) during teaching training, as well as suggest the necessity of more research on the subject.

Keywords: Active Methodologies; Blended Learning; Pedagogical and Epistemological Models.

\section{INTRODUÇÃO}

O deslocamento no papel do professor, crucial para uma prática pedagógica que acompanhe a sociedade e os alunos que temos hoje (GUERRA; BALBINO; MOREIRA, 2017), não é solucionado apenas pela adoção da tecnologia, pois sem a reflexão sobre as concepções epistemológicas, a tecnologia não altera paradigmas educacionais.

A educação tradicional conforme conhecemos, ainda presente em muitas escolas, foi concebida para um tipo de sociedade que não existe mais, pois atualmente demanda-se que as pessoas sejam ativas, autônomas, criativas, saibam trabalhar em equipe, tomem decisões com criticidade e sejam resilientes (MICHELS, 2014). Como professores, acreditamos que um caminho para desenvolver cidadãos mais atuantes socialmente seja através da educação. Por isso, consideramos de extrema importância repensar o ensino para a sociedade atual e educar para o mundo que virá (LEFFA, 1999), pelo aproveitamento pleno da natureza interativa das 
tecnologias digitais e da mudança na concepção de ensino e aprendizagem. Essa mudança deve estar aliada a uma epistemologia construtivista, centrada em uma participação ativa dos alunos, envolvendo-os plenamente no processo de ensino e aprendizagem, fator que acreditamos ser possível conquistar através de metodologias ativas como o Ensino Híbrido (KIELING, 2017).

A tecnologia faz parte das experiências vividas pelas pessoas em todos os contextos, desde engajar-se numa infinidade de sites de redes sociais com amigos, até o trabalho, o estudo ou a participação na vida familiar; é difícil encontrar uma área da vida que não tenha mudado (BARTON; LEE, 2015, p.12). Assim, julgamos importante que além do reconhecimento do impacto da tecnologia na forma como nossos alunos interagem com o mundo e da utilização da tecnologia em sala de aula, repensemos nossa prática com relação a como e para quem ensinamos, visando qualificar os resultados de aprendizagem e o engajamento dos estudantes (STEIN; GRAHAM, 2014).

Para tentar compreender a questão do ensino de línguas em formato híbrido, sumariamente entendido como uma experiência de aprendizagem que integra o presencial e o on-line (HORN; STAKER, 2015), sentimos necessidade de 
pensar não só a questão da prática pedagógica, mas também a questão epistemológica, que envolve a discussão e construção do conhecimento sobre a utilização da tecnologia em contexto educacional. Por mais presente que esteja a tecnologia, é importante salientar que o foco deve ficar na aprendizagem como objetivo último, e não na tecnologia, que é apenas um meio, e que deve ser o menos saliente possível para que não se desvie do que deve ser o motivo de sua adoção: o estudante. Desse modo, consideramos importante que a formação docente trate de modelos epistemológicos e pedagógicos, pois quando esses modelos estiverem ausentes, o professor tende a ser refém do senso comum, o que pode levá-lo a conduzir sua aula conforme práticas antigas, que podem até ter contribuído para a evolução da aprendizagem, mas que não têm mais razão de ocupar posição central no mundo contemporâneo. Sem tal problematização, provavelmente não obteremos a mudança desejada no processo pedagógico com a implantação do Ensino Híbrido, de celulares ou da internet. A conexão que demandamos obterá êxito se acompanhada de um esforço no sentido de compreendermos a forma como ensinamos, como construímos conhecimento e, por consequência, de mudança profunda na concepção de aprendizagem (BECKER, 2012). 
Este artigo está dividido em quatro seções, além desta introdução e das considerações finais, assim organizados: (1) modelos pedagógicos e epistemológicos, (2) Ensino Híbrido, (3) Metodologia, (4) análise e discussão dos dados.

\section{MODELOS PEDAGÓGICOS E EPISTEMOLÓGICOS}

Nesta seção apresentaremos os Modelos Pedagógicos e Epistemológicos propostos por Becker (2012), texto em que o autor sintetiza a discussão sobre os modelos epistemológicos que embasam os pedagógicos, conforme a Figura 1:

\section{MODELO A MODELO B MODELO C}

PEDAGOGIA

EPISTEMOLOGIA
Diretiva

Empirista
Não-Diretiva

Relacional

Apriorista

Relacional

Figura 1 - Modelos Pedagógicos e Epistemológicos.

Na Figura 1, elaborada pelos autores do presente trabalho, com base em Becker (2012), vemos que na Pedagogia Diretiva encontraremos uma sala de aula cujos alunos estarão dispostos em fileiras suficientemente afastadas umas das outras para evitar conversas. A palavra é do professor, portanto, enquanto este fala, o aluno escuta. O professor age assim porque acredita na transmissão do conhecimento, logo se ele ensinar, seu aluno irá aprender, restando, assim, 
ao aluno, submeter-se à fala do professor. O perfil do aluno conforme esta epistemologia empirista é totalmente definido pelas ações do professor. O indivíduo, para esse professor, frente a cada novo conteúdo é uma folha em branco. Esta pedagogia legitimada pela epistemologia empirista enfatiza um aluno anulado e inativo.

Na linguagem epistemológica proposta por Becker (2012) falaremos de sujeito e objeto. O sujeito, neste caso, é o elemento conhecedor, ativo, ou seja, o professor, o núcleo de onde se origina o conhecimento. Nessa relação, ensino e aprendizagem são polos dicotômicos: o professor jamais ensinará e o aluno jamais aprenderá e, conforme vimos, o professor age dessa forma embasado pedagogicamente.

Na Pedagogia Não Diretiva, o professor acredita que o aluno aprende por si mesmo e que ao intervir irá prejudicar o processo. Assim como no modelo anterior, a atitude deste professor é fundamentada na epistemologia apriorista. "Apriorismo" vem de a priori e, conforme o próprio nome sugere, essa epistemologia acredita que o ser humano nasce com o conhecimento já programado em sua herança genética. Como tudo já está previsto, o professor, "renuncia àquilo que seria a característica fundamental da ação docente: a intervenção no processo de aprendizagem do aluno" (BECKER, 2012, p.18-19). 
O aluno, pelas suas condições prévias, motiva a ação ou omissão do professor. O resultado é um pseudo processo educacional que caminha para o fracasso de ambos. Sendo assim, Becker (2012) afirma que o caminho para tornar possível a superação dos modelos apresentados acima é o da crítica epistemológica relacional.

Na Pedagogia Relacional, o professor apresenta algum material, o qual acredita ser significativo para o aluno, e propõe a exploração e a troca de ideias sobre esse artefato, revestindo de extrema importância seu papel de educador. Age assim porque acredita que o aluno só construirá conhecimento novo se atuar. Espera-se que 0 aluno problematize sua ação, ou seja, responda às provocações pela assimilação de tal material, apropriando-se dele. O professor sabe que há duas condições para que o conhecimento seja construído: (a) Que o aluno aja (assimilação) sobre o material e (b) Que o aluno responda a si mesmo (acomodação) às perturbações causadas pela assimilação do material.

Professor e aluno estabelecem uma relação de colaboração, um pela ação do outro, e a aprendizagem é, por excelência, construção. Este professor não acredita no ensino em seu sentido tradicional, tampouco que o aluno seja uma tábula rasa, mas que tudo que ele tenha aprendido até 
então em sua vida serve de patamar à construção de novos conhecimentos. Neste modelo da Pedagogia Relacional a epistemologia também é relacional, concebendo esse aluno como capaz de aprender sempre.

Sendo assim, na sala de aula ultrapassa-se a disciplina policialesca e o dogmatismo do conteúdo pela construção de uma disciplina intelectual e regras de convivência, criando um ambiente abundante de aprendizagem. Na interação, o sujeito é ativo, tem iniciativa, pode tomar consciência de suas ações e pode operar, ou seja, organizar mentalmente suas ações.

Becker (2012) ressalta que apesar da oposição entre a Pedagogia Diretiva e Não-Diretiva, ambas têm um ponto em comum: a passividade do sujeito. No primeiro, o sujeito não precisa agir, pois herdou tudo e, no segundo, porque o meio dará tudo. Assim, o autor conclui o quão inadequadas essas posturas epistemológicas são para promover uma visão da capacidade humana de aprender e, por isso, coloca que a aprendizagem não pode mais ser debitada ao ensino e sim à ação do sujeito. Acreditamos que o ensino deva ser repensado em função dessa nova concepção de aprendizagem: considerando como central a atividade do sujeito, característica que as metodologias ativas com 
as modalidades do Ensino Híbrido de Rotação (conforme veremos adiante) têm possibilidade de construir no processo pedagógico.

\section{ENSINO HÍBRIDO}

Moran (2017) pontua queaprendemosquando alguém mais experiente nos fala e também a partir de um envolvimento mais direto, por questionamento e experiências. Contudo, o autor afirma que as metodologias predominantes de ensino são as dedutivas em que o professor transmite primeiro a teoria e depois o aluno a aplica em situações específicas. A partir disso, o autor constata que a aprendizagem por meio da transmissão é importante, mas aquela por questionamento e experimentação é mais relevante para uma compreensão mais ampla e profunda.

Em decorrência disso, Moran (2017), nos diz que nos últimos anos, há uma ênfase em combinar metodologias ativas em contextos híbridos e faz a ressalva de que pesquisas atuais em neurociência comprovam que o processo de aprendizagem é único e diferente para cada ser humano e que cada pessoa aprende o que é mais relevante e o que faz sentido para si, o que encontra ressonância íntima, o que está próximo do estágio de desenvolvimento em que nos encontramos. 
Segundo ele, de certa forma, toda aprendizagem é ativa em alguma medida, porque demanda do estudante e do docente formas diferentes de movimentação interna e externa, de motivação, seleção, interpretação, etc. Sendo assim, o professor como orientador ou mentor ganha relevância, pois seu papel é ajudar os alunos a irem além de onde conseguiriam ir sozinhos.

Moran (2017) destaca ainda que a combinação equilibrada da flexibilidade da aprendizagem híbrida com metodologias ativas facilita a ampliação de nossa percepção e competência em todos os níveis e reforça que as sociedades mais dinâmicas são as que incentivam a colaboração, o empreendedorismo e a criatividade. Além disso, o uso de abordagens híbridas se apresenta como proeminente para combater o problema da falta de integração crítica de tecnologias na educação (KEENGWE; KANG, 2013; FINARDI; MENDES, 2017).

Apesar de o uso de tecnologias ser previsto em documentos oficiais como os Parâmetros Curriculares Nacionais - PCN (BRASIL, 1997) e mais recentemente a Base Nacional Comum Curricular - BNCC (BRASIL, 2016), a sua utilização não só está aquém do esperado como também sendo feita de forma muito instrumental (FERRAZ, 2014), tornando a prática pedagógica sem ressonância para o educando e contribuindo para um 
cenário de insatisfação coletiva. Os estudantes reclamam das aulas rotineiras, enfadonhas e pouco dinâmicas, enquanto que os professores queixam-se da frustração pela pouca participação, desinteresse e desvalorização dos estudantes em relação às aulas e às estratégias criadas para chamar sua atenção. Percebe-se que a simples utilização de tecnologia nas aulas não altera esse panorama, atestando que, estas por si só não transpõem velhos paradigmas. Por isso, a ação proposta para ensinar não pode ser desconectada daqueles que dela participarão, enfatizando a necessidade de os docentes buscarem novas metodologias de ensino que foquem no protagonismo dos alunos. É nesta perspectiva que se situa a metodologia ativa, deslocando a perspectiva do ensino (professor), para a aprendizagem (aluno) (DIESEL et al., 2017).

Enquanto as metodologias mais tradicionais eram baseadas na transmissão de informações e no papel central do docente, as metodologias ativas buscam a construção e colaboração dos estudantes, estimulam a reflexão, a autonomia e a pesquisa. Sendo assim, os autores Diesel et al. (2017) apontam os princípios das metodologias ativas de ensino como: (a) aluno como centro do processo de aprendizagem, (b) autonomia a partir da postura mais 
ativa do estudante, (c) problematização da realidade e reflexão a partir da busca pela integração dos conteúdos com o contexto social, (d) trabalho em equipe a partir das atividades propostas que visam favorecer a interação constante entre os alunos, (e) inovação a partir da crença de que tais metodologias exigem ousadia e coragem dos professores e (f) professor mediador a partir da constatação de que este assume uma postura investigativa da própria prática e da concepção de que a prática pedagógica é essencialmente formadora. Nesse sentido, entendemos que as características das metodologias ativas vêm ao encontro de uma pedagogia relacional, conforme apresentado em etapas anteriores deste trabalho.

Consideramos o Ensino Híbrido uma possibilidade interessante de intervenção, de inovação sustentada na realidade das práticas pedagógicas e a definição adotada é a de que o Ensino Híbrido é um programa de educação formal no qual o aluno aprende, pelo menos em parte, online, com algum elemento de controle do aluno sobre o tempo, lugar e/ou ritmo e, pelo menos em parte, em um local físico, supervisionado; é, sobretudo, uma experiência de aprendizagem integrada que propõe unir o antigo com o novo: presencial e on-line (HORN; STAKER, 2015). 
As modificações possibilitadas pelas tecnologias digitais requerem novas metodologias de ensino, as quais necessitam de novos suportes pedagógicos, transformando e deslocando o papel do professor e dos estudantes e ressignificando o conceito de ensino e aprendizagem. O que se observa é que o ambiente físico das salas de aula não se modificou significativamente, uma vez que, embora tenhamos uma lousa digital, alguns computadores e celulares, os alunos continuam sentados em suas classes com um professor à frente. Porém, é a interação gerada por essas tecnologias que pode (re)criar e ampliar o espaço da sala de aula para além da formatação tradicional e dos próprios limites escolares (BACICH et al., 2015).

O Ensino Híbrido é uma excelente oportunidade de ressignificação desse ambiente, pois ao inserir a tecnologia, "preservam-se as paredes" e pode ser uma inovação sustentada da sala de aula, visto que concilia o melhor dos dois mundos: presencial e on-line (HORN; STAKER, 2015). Os espaços da escola e da sala de aula, apesar de suas divisórias, não precisam ser limitadores do trabalho do professor. Para que isso se altere, é necessário que este tome a responsabilidade da mudança para si e busque parcerias tanto com outros educadores, quanto junto à coordenação 
da escola. Além disso, vários estudos (PAIVA, 2013; ARRUDA, 2013; FINARDI; MENDES, 2017; KIELING, 2017) apontam a necessidade da integração das tecnologias digitais através da prática do professor formador ainda na formação inicial visando fomentar práticas docentes futuras.

O Ensino Híbrido tem quatro modelos, de acordo com a definição de Horn e Staker (2015): (1) Modelo de rotação, (2) Modelo flex, (3) Modelo à la carte e (4) Modelo Virtual Enriquecido, conforme podemos visualizar na Figura 2:

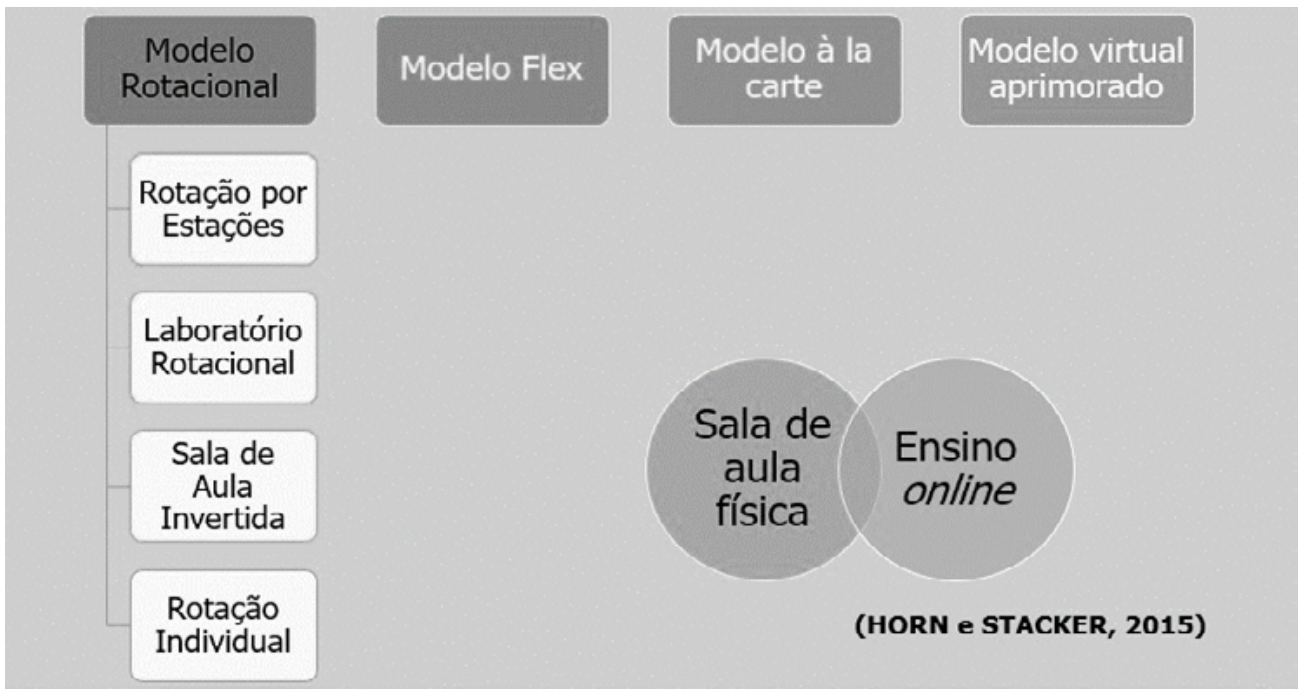

Figura 2 - Modelos de Ensino Híbrido.

A Figura 2 mostra que o modelo de Rotação por Estações organiza os estudantes em grupos, de modo que cada um realize uma tarefa de acordo com os objetivos propostos 
para a aula em questão. Após um determinado tempo, previamente combinado com os estudantes, eles trocam de grupo, e esse revezamento continua até todos terem passado por todos os grupos. No Laboratório Rotacional, os estudantes usam o espaço da sala de aula e laboratórios. 0 modelo começa com a sala de aula tradicional e, em seguida, adiciona uma alternância para computador ou laboratório de ensino. No modelo da Sala de Aula Invertida a teoria é estudada em casa, no formato on-line, e o espaço da sala de aula é utilizado para discussões, resolução de problemas, entre outras atividades. Esse modelo é também valorizado como a porta de entrada para o Ensino Híbrido. Tais modelos são considerados de inovação sustentada para a sala de aula, pois conciliam o ensino tradicional com o on-line. Ainda assim, é indispensável que haja uma transformação na atuação do professor e do aluno para que esse novo espaço seja significativo.

No modelo de Rotação temos também a Rotação Individual em que cada aluno tem um cronograma próprio e não alterna obrigatoriamente entre cada estação. No entanto, este modelo rompe totalmente com o sistema tradicional de ensino e, por isso, é considerado de inovação disruptiva. 
Os modelos seguintes sugerem a aprendizagem on-line como eixo condutor do processo de ensino, a começar pelo modelo Flex, em que o curso ou disciplina on-line é a espinha dorsal da aprendizagem, mesmo que direcione o aluno para atividades presenciais. Cada estudante tem um cronograma fluido e personalizado entre as modalidades de aprendizagem. O professor é presencial e ele ou outro adulto oferece apoio em uma base presencial, flexível e adaptada quando necessário. Fazer um curso totalmente online que acompanhe outras experiências na escola regular com professor on-line são as especificidades do Modelo à la carte. O nome vem da característica desta modalidade em que o aluno pode escolher um curso entre inúmeras opções. No modelo Virtual Enriquecido os estudantes têm sessões presenciais obrigatórias com professor presencial e complementam o trabalho de forma on-line quando estão fora da escola.

\section{METODOLOGIA}

Para o desenvolvimento deste estudo foi escolhida a abordagem qualitativa com os princípios do Estudo de Caso. Conforme observado por Bogdan e Biklen (1994), uma pesquisa qualitativa pode ser definida com base em cinco características: a importância do ambiente natural para 
coleta de dados, os dados predominantemente descritivos, a preocupação maior com o processo do que com o produto, a consideração da perspectiva participante e a tendência de a análise seguir um processo indutivo.

Utilizamos os princípios do Estudo de Caso que segundo a concepção das autoras Lüdke e André (1986), “(...) é o que se desenvolve numa situação natural, é rico em dados descritivos, tem um plano aberto e flexível e focaliza a realidade de forma complexa e contextualizada". Não se investiga uma variável isolada; procura-se, ao contrário, descrever todos os aspectos que envolvem a pesquisa, sendo assim um tipo de pesquisa qualitativa com ênfase maior na exploração e descrição detalhada de um determinado evento ou situação, sem a preocupação de descobrir uma verdade universal e generalizável. Suas aplicações pretendem estender-se à educação, como técnica de ensino e à clínica, como instrumento de trabalho (LEFFA, 2006).

A pesquisa foi realizada no Curso de Extensão de Língua Inglesa de uma Universidade Federal do Sul do Brasil. Neste curso, os professores são alunos da graduação, ou seja, professores em formação, que têm a possibilidade de aprender sobre a prática docente de forma orientada por um professor do curso de Letras. Para preservação da 
identidade das professoras em formação na descrição dos resultados foram dados nomes fictícios: "Carla" e "Júlia". O estudo foi realizado em duas turmas do curso: uma de nível Inglês Básico I e outra de Inglês Básico II. A primeira era composta de 22 alunos e, a segunda, de 27 alunos. Ambas eram majoritariamente integradas por universitários.

Foram utilizados diversos instrumentos: entrevista inicial e final, ambas semiestruturadas com as participantes, diário de bordo dos encontros de orientação, grupo de WhatsApp com as participantes, entrevista semiestruturada com parte dos alunos de cada turma e observações de aula. Além disso, os sujeitos de pesquisa utilizaram com seus alunos grupos na rede social Facebook e no aplicativo WhatsApp que também serviram de recurso para coleta de dados. Assim como Arruda (2013 Apud FINARDI; MENDES et al. 2017), entendemos que as ações educacionais "precisam ser mediadas pelos suportes comunicacionais característicos da sociedade contemporânea, já que eles configuram como estruturantes simbólicos da vida humana.".

Após duas semanas de trabalho das professoras em formação com o plano de aula, foi possível iniciar a aplicação dos instrumentos para reflexão sobre a implementação do Ensino Híbrido, dos quais faziam parte: (a) Identificação 
dos problemas e objetivos, (b) Construção da experiência discente e docente e (c) Construção dos espaços físico e virtual. Como os encontros eram semanais foram necessárias quatro semanas até concluir esta fase. Além de serem encontros semanais, por serem professoras em formação e na sua primeira experiência em sala de aula, percebia-se que este espaço de tempo para reflexão era necessário, pois cada passo levava cerca de uma hora de discussão. Cabe salientar que nosso interesse era por um processo construído junto com as professoras em formação e não como algo imposto pela pesquisadora, de modo que todas as questões eram problematizadas e debatidas conjuntamente. A pesquisa também teve compromisso com a formação docente dessas participantes, considerando formação no sentido de Leffa (1999): um processo continuamente mais complexo, a fusão do conhecimento recebido com o experimental e uma preparação para o futuro, pois dessa forma, acreditamos contribuir também para a autonomia delas no processo de formação docente. Por esse motivo também, os instrumentos Facebook e WhatsApp foram utilizados nesta pesquisa, pois no primeiro encontro com as participantes, elas já haviam criado estes grupos e escolhido estas ferramentas para comunicação extraclasse com os alunos. Neste estudo constituiu-se um desafio tornar estes 
grupos em ferramentas de aprendizagem, para além de grupo de recados entre alunos e professoras em formação.

\section{ANÁLISE E DISCUSSÃO DOS DADOS}

No primeiro instrumento de reflexão, utilizado para identificar problemas e objetivos, ambas as professoras em formação colocaram como um limite a falta de contato dos alunos com a língua inglesa e de participação nos grupos de Facebook e WhatsApp durante a semana, bem como a falta de uma produção escrita e oral mais ampla na língua alvo. Quanto aos resultados desses aspectos, após a implementação, as participantes relataram que foi observável a melhoria na habilidade de produção oral dos alunos, bem como a expansão do espaço e tempo da sala de aula fazendo com que os alunos mantivessem contato mais frequente com a língua alvo. Em contrapartida, também foi observado pelas professoras em formação que se esperava maior autonomia dos alunos, por se tratar de nível universitário, o que não foi constatado, sugerindo mais uma vez a importância da utilização das metodologias ativas na educação básica. Isso corrobora o pensamento de Paiva (2013) que propõe parâmetros a serem considerados na formação docente, tais como a incorporação das tecnologias pelos professores formadores, a criação de disciplinas que usem e discutam as tecnologias e a prática pedagógica com o uso dessas na educação básica. 
No segundo instrumento utilizado para reflexão, as professoras em formação foram chamadas a pensar sobre o que um aluno espera ao se matricular no curso de idiomas. Nessa etapa, ambas afirmaram que seria desenvolver a comunicação em língua inglesa. Após isso, discorreram sobre de que forma o Ensino Híbrido poderia contribuir com tal expectativa e as respostas foram relacionadas aos grupos on-line e à atividade de Rotação por Estações que elas iriam implementar. Com relação aos grupos on-line, as participantes avaliaram que a integração destes com a sala de aula presencial contribuiu para a aprendizagem dos alunos. A professora em formação, Julia, atribuiu a sua percepção ao relato positivo dos alunos nas pesquisas de satisfação, enquanto que a Carla a percebeu com base em resultados pedagógicos ressaltando o aumento do vocabulário e a conexão realizada por alguns estudantes dos espaços presencial e on-line para sua aprendizagem. Nesse sentido, Carla confirma pesquisas (ZHANG et al. 2011; KHAZAEI; DASTJERDI, 2011) que listaram muitos benefícios sobre a aprendizagem de vocabulário em língua estrangeira utilizando o Ensino Híbrido com resultados superiores em testes comparados a alunos que apenas tiveram instrução tradicional. 
Com relação ao esperado da atuação do professor, as professoras em formação, apesar de terem motivações diferentes, desejavam aplicar a Rotação por Estações por acreditarem que este modelo proporcionaria uma maior autonomia dos alunos. Além disso, ambas definiram que propor as atividades on-line e relacioná-las com a sala de aula física seria essencial para uma implementação bem-sucedida do Ensino Híbrido. Os relatos apresentados por elas, mesmo sendo professoras iniciantes e em formação, demonstraram que conseguiram realizar o que se propuseram a fazer a partir deste instrumento de reflexão e ambas reconheceram os grupos on-line como ferramentas que contribuíram para a aprendizagem dos alunos, algo que também foi reconhecido pelos estudantes conforme pode ser apreciado na versão estendida da pesquisa em Kieling (2017).

Quando questionadas sobre sua relação com a tecnologia na entrevista inicial, as professoras em formação relataram utilizá-la diariamente e estarem sempre conectadas, principalmente através do celular. Apesar disso, ambas apresentam perfis diferentes de utilização das ferramentas, pois pudemos perceber, por meio da entrevista, que a participante mais madura, Carla, ainda precisa bastante do suporte do papel para realizar suas atividades acadêmicas, 
por exemplo, enquanto que a outra, dez anos mais jovem, basicamente acessa o que precisa pelo meio digital, sem imprimir qualquer material.

Contudo, tal fato não apresentou diferença no momento de aplicação da tecnologia para a prática pedagógica. Apesar dos perfis diferentes, a utilização dos recursos tecnológicos no ensino de língua inglesa provavelmente não teria sido explorada, confirmando o que Becker (2012) nos dizia sobre a necessidade de a formação docente refletir sobre modelos epistemológicos e pedagógicos. Essa reflexão, quando ausente, deixa o professor refém do senso comum e, assim, inconsciente do seu fazer e seu pensar (BECKER, 2012). Dito de outra forma, irá conduzir sua aula somente conforme práticas antigas, que já tiveram sua contribuição em outros tempos; da mesma forma Paiva (2013) alerta para que o exemplo deve vir dos professores formadores. No entanto, ambas as professoras em formação tiveram e, segundo as próprias, continuam tendo seu repertório como alunas em contextos com pouca ou nenhuma utilização desses recursos. Apesar de estarem sempre conectadas, provavelmente não iriam aplicar esse recurso com suas turmas em sua prática docente, relato que corrobora Bacich et al. (2015, p.51) quando afirmam que "as modificações possibilitadas 
pelas tecnologias digitais requerem novas metodologias de ensino, as quais necessitam de novos suportes pedagógicos, transformando o papel do professor e dos estudantes e ressignificando o conceito de ensino e aprendizagem.".

Em entrevista realizada com uma das participantes evidenciamos a afirmação de Bacich e Moran (2017) de que muitos professores utilizam recursos de forma restrita à preparação das aulas. Segundo a autora “(...) estudos revelam que professores têm usado as tecnologias digitais e sentido mais confiança nessa utilização, mas, na maioria das vezes, o uso é restrito à preparação de aulas; poucos deles utilizam esses recursos para trabalhar com os estudantes durante as aulas (...)". Dessa forma, mais uma vez, a implementação do Ensino Híbrido provou-se relevante. Primeiro pela oportunidade de prática pedagógica refletida utilizando recursos tecnológicos durante a formação docente, fator que julgamos essencial para transformação das práticas pedagógicas futuras e, segundo, porque apesar de serem professoras em formação em um contexto de mundo cercado por tecnologias, elas iriam seguir os modelos de ensino a que foram e estavam sendo submetidas enquanto alunas, com a utilização de novos recursos para velhos usos.

Apesar de terem aplicado quizzes bastantes simples, sem usarem plenamente os recursos digitais, o que deve 
ser ressaltado nesta pesquisa é a integração dos espaços físico e virtual através dessas atividades, que foi algo bemsucedido, resultando, conforme Horn e Staker (2015), na oportunidade de ressignificação desse ambiente [da sala de aula], pois pode ser uma inovação sustentada da sala de aula por conciliar o melhor dos dois mundos: presencial e on-line. Além disso, as professoras em formação relataram que a ação dos alunos foi mais valorizada; visto que eles, com seus respectivos dispositivos móveis participavam ativamente do que fora proposto por elas.

A escolha da rede social Facebook e do aplicativo WhatsApp deram-se pela facilidade de acesso e pela possibilidade de interação entre os alunos e dos alunos com o professor, conforme as professoras em formação relataram nos instrumentos construindo os ambientes físico e virtual. Na percepção delas, esses espaços funcionaram como complementares da sala de aula física, corroborando a perspectiva de Horn e Staker (2015) e Finardi e Mendes. (2017) que também sugere a utilização desses aplicativos como complemento do aprendizado presencial em abordagens híbridas.

Buscávamos, com a Rotação por Estações (HORN; STAKER, 2015), uma participação mais intensa dos alunos 
e um deslocamento no papel do professor, visando que neste momento este mediasse mais o processo pedagógico e que, aqueles atuassem mais autonomamente com seus colegas. Ambas professoras em formação perceberam que o Ensino Híbrido foi uma experiência que contribuiu para o protagonismo do aluno, especialmente nas atividades de Rotação por Estações em que perceberam a agência e colaboração dos alunos.

\section{CONSIDERAÇÕES FINAIS}

O objetivo geral desta pesquisa foi investigar a implementação do modelo Ensino Híbrido (Blended Learning) de Rotação (HORN; STAKER, 2015) em um curso de extensão de Língua Inglesa, ministrado por professoras em formação de uma Universidade Federal do Sul do Brasil. Durante esse processo, foi possível perceber a importância da fundamentação de uma concepção epistemológica e pedagógica relacional para embasar a utilização de metodologias ativas - das quais, vale destacar, o Ensino Híbrido faz parte -, pois é fundamental que o professor conceba o processo pedagógico construído em conjunto com os alunos, para que a ação dos alunos seja colocada como central durante todo processo.

A fim de alcançar esse objetivo mais amplo que acabamos de descrever, delimitamos três objetivos específicos, a saber: 
(a) Apresentar os modelos pedagógicos e epistemológicos que norteiam a atividade docente, com ênfase no uso pedagógico de tecnologias; (b) Relacionar os modelos pedagógicos e epistemológicos apresentados a priori ao conceito de metodologias ativas, com destaque para o Ensino Híbrido; e (c) Avaliar em que medida os modelos epistemológicos e pedagógicos, juntamente com metodologias ativas como o Ensino Híbrido, podem potencializar o uso pedagógico de tecnologias na formação inicial de duas professoras.

Desse modo, em um primeiro momento do estudo, desenvolvemos, na seção "Modelos Pedagógicos e Epistemológicos" uma discussão a respeito dessa perspectiva, com base em Becker (2012). Tais modelos podem ser resumidos da seguinte maneira: (a) Modelo A: Pedagogia Diretiva e Epistemologia Empirista; (b) Modelo B: Pedagogia Não-Diretiva e Epistemologia Apriorista; e (c) Modelo C: Pedagogia Relacional e Epistemologia Relacional.

Com vistas a responder ao segundo objetivo específico do trabalho, ou seja, "b) relacionar os modelos pedagógicos e epistemológicos apresentados a priori ao conceito de metodologias ativas, com destaque para o Ensino Híbrido", relacionamos nas seções "Ensino Híbrido" e "Metodologias Ativas", esses dois conceitos ao modelo 
pedagógico e epistemológico relacional, uma vez que, na nossa interpretação, seria o único capaz de contemplar o uso de tecnologias de acordo com os princípios discutidos anteriormente.

Com relação ao terceiro objetivo específico deste trabalho, qual seja, "c) Avaliar em que medida os modelos epistemológicos e pedagógicos, juntamente com metodologias ativas como o Ensino Híbrido, podem potencializar o uso pedagógico de tecnologias na formação inicial de duas professoras", chegamos a diversas conclusões, conforme recuperamos doravante.

Em primeiro lugar, vale destacar que essa experiência trouxe problematizações novas paras as professoras em formação, que, inclusive, relataram a falta de articulação pedagógica com relação à tecnologia em suas experiências enquanto discentes. Nesse processo, podemos afirmar que as tecnologias digitais podem colaborar para 0 ensino e aprendizagem quando combinadas com a sala de aula presencial. Entre os principais resultados estão o enriquecimento da prática pedagógica das professoras em formação, a integração dos alunos através dos grupos de WhatsApp e Facebook como espaços educacionais e a motivação dos alunos por meio das atividades propostas. 
Em segundo lugar, este trabalho, pelos resultados que apresentou, sugere a necessidade de investir na formação inicial docente com uso de tecnologias e que este seja tema de discussões e estágio propostas pelos formadores. Nesse sentido, ao reconstruir a reflexão sobre os modelos pedagógicos e epistemológicos de Becker (2012), fica evidente a superioridade do modelo Relacional sobre os outros. Como discurso, talvez isso seja quase um lugar comum. No entanto, para se efetivar como prática, há a necessidade de se propor novas formas de organizar a sala de aula, e esta pesquisa mostrou uma dessas experiências que, além de propiciar a ação dos estudantes, é mediada por novas tecnologias.

Por fim, o interessante é trabalhar a partir de uma perspectiva relacional, incluindo essas novas tecnologias. Observa-se, nesse sentido, que a tecnologia na sala de aula por si só não resolve o problema, mostrando ser necessário repensar a dinâmica de ensino, tanto em sala de aula quanto fora dela, a fim de trabalhar relacionalmente a mediação tecnológica, aspectos que o Ensino Híbrido de Rotação conseguiu cumprir com sucesso.

\section{REFERÊNCIAS}

ARRUDA, Eucidio Pimenta (2013). “Ensino e aprendizagem na sociedade do entretenimento: desafios para a formação docente". In: Revista Educação, 36(2), p.232-239, mai./ago. Porto Alegre: Pontifícia Universidade Católica do Rio Grande do Sul. 
BACICH, Lilian; NETO, Adolfo Tanzi; TREVISANI, Fernando de Mello (Orgs.) (2015). Ensino Híbrido: Personalização e tecnologia na educação. Porto Alegre: Penso.

BARTON, David; LEE, Carmen (2015). Linguagem online: textos e práticas digitais. Milton Camargo Mota (Trad.). São Paulo: Parábola.

BECKER, Fernando (2012). Educação e construção do conhecimento. 2.ed. Porto Alegre: Penso.

BOGDAN, Robert; BIKLEN, Sari (1994). Investigação Qualitativa em Educação: uma introdução à teoria e aos métodos. Porto: Porto Editora. BRASIL, Ministério da Educação (1997). Parâmetros Curriculares Nacionais para o Ensino Fundamental. Brasília, DF.

(s/d) Ministério da Educação. Secretaria de Educação Básica (2016). Base Nacional Comum Curricular. Brasília, DF. In basenacionalcomum. mec.gov.br/\#site/inicio Acesso em Abr.2019.

DIESEL, Aline; BALDEZ, Alda Leila Santos; MARTINS, Silvana Neumann (2017). "Os princípios das metodologias ativas de ensino: uma abordagem teórica". Revista Thema, 14(1), 268-288. Pelotas: Instituto Federal de Educação, Ciência e Tecnologia Sul-rio-grandense.

FERRAZ, Daniel de Mello (2014). "Novos letramentos e educação de línguas estrangeiras: problematizações e desafios". In: STELLA, Paulo Rogério; CAVALCANTI, Ildney; TAVARES, Roseanne; IFA, Sérgio. (Orgs.). Transculturalidade e De(s)colonialidade nos Estudos em Inglês no BraZil. 1.ed. Maceió: Edufal, p.53-84.

FINARDI, Kyria; MENDES, Ana Rachel (2017). "Formação de professores para uso de metodologias ativas e híbridas através do MALL". Hipertextus Revista Digital, 16, 52-74, jun.

GUERRA, Francismara Fernandes; BALBINO, Carlito Arlindo dos Santos; MOREIRA, Ana Maria Álvares Martins (2017).“Tecnologias e currículo: impactos na prática educativa e no papel do professor". Plures Humanidades, 18(1), 75-93.

HORN, Michael; STAKER, Heather (2015). Blended: usando a inovação disruptiva para aprimorar a educação. Maria Cristina Gularte Monteiro (Trad.). Porto Alegre: Penso. 
KEENGWE, Jared; KANG, Jung-Jin (2013). "A review of empirical research on blended learning in teacher education programs". Education and Information Technologies, 18(3), 479-493.

KIELING, Helena dos Santos (2017). Blended learning no ensino de inglês como Língua Estrangeira: um estudo de caso com professoras em formação. 84f. (Dissertação de Mestrado) - Programa de Pós-graduação em Letras. Pelotas: Universidade Católica de Pelotas.

KHAZAEI, Said; DASTJERDI, Hossein Vahid (2011). "An Investigation into the Impact of Traditional vs. Blended Teaching on EFL Learners' Vocabulary Acquisition: M-learning in Focus". International Journal of Humanities and Social Science, 1(15), p.202-207.

LEFFA, Vilson José (1999). "O Ensino de línguas estrangeiras no contexto nacional”. Contexturas, 4(4), p.13-24. São Paulo: APLIESP.

(2006). "Aprendizagem de línguas mediada por computador". In: ______ (Org.). Pesquisa em Linguística Aplicada: temas e métodos. Pelotas: Educat.

LÜDKE, Menga; ANDRÉ, Marli Eliza Dalmazo Afonso de (1986). Pesquisa em educação: abordagens qualitativas. São Paulo: EPU.

MICHELS, Ana Beatriz (2014). Do fazer ao compreender no contexto da educação a distância: uso de arquiteturas pedagógicas no processo de empreender. 186f. Dissertação (Mestrado) - Programa de Pós-graduação em Educação. Porto Alegre: Universidade Federal do Rio Grande do Sul.

MORAN, José (2018). Metodologias ativas para uma aprendizagem mais profunda. In: $\mathrm{BACICH}$, Lilian; MORAN, José (Orgs.). Metodologias ativas para uma educação inovadora: uma abordagem teórico-prática [recurso eletrônico]. Porto Alegre: Penso.

PAIVA, Vera Lúcia Menezes de Oliveira e (2013). "A formação do professor para uso da tecnologia". In: SILVA, Kleber Aparecido da; DANIEL, Fátima de Gênova; KANEKO-MARQUES, Sandra Mari; SALOMÃO, Ana Cristina Biondo (Orgs.). A formação de professores de línguas: Novos Olhares Vol.2. p.209-230. Campinas, SP: Pontes Editores. 
SCHNEIDER, Fernanda (2015). "Otimização do espaço escolar por meio do ensino híbrido". In: BACICH, Lilian; NETO, Adolfo Tanzi; TREVISANI, Fernando de Mello (Orgs.). Ensino Híbrido: personalização e tecnologia na educação. Porto Alegre: Penso.

STEIN, Jared; GRAHAM, Charles (2014). Essentials for blended learning: a standards-based guide. New York: Routledge.

ZHANG, Haisen; SONG, Wei; BURSTON, Jack (2011). "Reexamining the effectiveness of vocabulary learning via mobile phones". The Turkish Online Journal of Educational Technology, 10(3), p.203-214

André Firpo Beviláqua é Mestre em Letras pela Universidade Católica de Pelotas UCPel. Atualmente realiza seu Doutorado em Letras pela Universidade Federal de Pelotas ( UFPel, com bolsa CAPES, sob a supervisão do Prof. Dr. José Vilson Leffa. Tem experiência na área de Letras, com ênfase em Linguística Aplicada Crítica e Ensino Crítico de Línguas, atuando principalmente com os seguintes temas: a) Letramentos Críticos; b) Materiais de Ensino e Recursos Educacionais Abertos (REA); c) Formação de educadores; d) Educação Popular; e) Tecnologias digitais no ensino de línguas; f) Educação a Distância. E-mail: andre.firpo@gmail. com.

Helena dos Santos Kieling é Mestre em Letras pela UCPel. Atualmente, realiza seu Doutorado em Letras na UFPel, sob a supervisão do Prof. Dr. Rafael Vetromille-Castro. Tem experiência na área de Letras, com ênfase em Linguística Aplicada e ensino de línguas, atuando principalmente com os seguintes temas: a) Metodologias ativas; b) Ensino híbrido; c) Formação docente; d) Tecnologias digitais no ensino de línguas.

E-mail: kieling.helena@gmail.com

Vilson José Leffa Doutor em Linguística Aplicada pela Universidade do Texas (1984). Trabalhou na Universidade Federal do Rio Grande do Sul UFRGS, na UCPel e foi pesquisador visitante na Universidade da Califórnia, em Irvine. Atualmente é professor visitante da UFPel. Possui experiência na área de Letras, com ênfase em Linguística Aplicada, atuando principalmente com os seguintes temas: a) Leitura; b) Produção Textual; 
c) Interação na sala de aula; d) Formação de professores; e) entre outros. Mais recentemente concentrou-se no estudo das tecnologias digitais no ensino de línguas, incluindo a produção de Recursos Educacionais Abertos (REA) e Educação a Distância.

E-mail: leffav@gmail.com

Recebido em 09 de abril de 2019. Aprovado em 09 de julho de 2019. 